\title{
Microstructural Changes and Effect of Variation of Lattice Strain on Positron Annihilation Lifetime Parameters of Zinc Ferrite Nanocomposites Prepared by High Enegy Ball-milling
}

\author{
Abhijit Banerjee ${ }^{\mathrm{a}}$,Srinjoy Bid ${ }^{\mathrm{b}}$, Hema Dutta $^{\mathrm{c}}$,Sandeep Chaudhuri ${ }^{\mathrm{d}}$, \\ Dipankar Das , Swapan Kumar Pradhan ${ }^{\text {a* }}$ \\ ${ }^{a}$ Department of Physics, The University of Burdwan, Golapbag, Burdwan-713104, West Bengal, India \\ ${ }^{\mathrm{b}}$ Department of Physics, Academy of Science, Aidco Nagar, Hooghly, West Bengal, India \\ ${ }^{\mathrm{c} D e p a r t m e n t ~ o f ~ P h y s i c s, ~ V i v e k a n a n d a ~ C o l l e g e, ~ B u r d w a n-713103, ~ W e s t ~ B e n g a l, ~ I n d i a ~}$ \\ ${ }^{\mathrm{d}}$ Department of Physics, University of Surrey, Guildford, Surrey, UK \\ ${ }^{\mathrm{e}} U G C$-DAE Consortium for Scientific Research, Kolkata 700098
}

Received: February 20, 2012; Revised: July 20, 2012

\begin{abstract}
$\mathrm{Zn}$-ferrite nanoparticles were synthesized at room temperature by mechanical alloying the stoichiometric $(1: 1 \mathrm{~mol} \%)$ mixture of $\mathrm{ZnO}$ and $\alpha-\mathrm{Fe}_{2} \mathrm{O}_{3}$ powder under open air. Formation of both normal and inverse spinel ferrite phases was noticed after 30 minutes and 2.5 hours ball milling respectively and the content of inverse spinel phase increased with increasing milling time. The phase transformation kinetics towards formation of ferrite phases and microstructure characterization of ball milled $\mathrm{ZnFe}_{2} \mathrm{O}_{4}$ phases was primarily investigated by X-ray powder diffraction pattern analysis. The relative phase abundances of different phases, crystallite size, r.m.s. strain, lattice parameter change etc. were estimated from the Rietveld powder structure refinement analysis of XRD data. Positron annihilation lifetime spectra of all ball milled samples were deconvoluted with three lifetime parameters and their variation with milling time duration was explained with microstructural changes and formation of different phases with increase of milling time duration.
\end{abstract}

Keywords: nano-Zn-ferrites, ball-milling, Rietveld method, positron annihilation

\section{Introduction}

Ferrites are a group of technologically important materials used in magnetic, electronic and microwave fields. Magnetic nanocrystalline materials hold great promise for atomic engineering of materials with functional magnetic properties ${ }^{1-3}$. Many magnetic nanocrystals show superparamagnetism in single domain particles below a certain critical size. Magnetic nanocrystals have been extensively applied in magnetic recording medium, information storage, bio-processing and magneto-optical devices ${ }^{4,5}$. The sulfur absorption capacity of milled zinc ferrite increases with decreasing crystallite size due to structure-reactivity relationship at high temperature.

Crystalline $\mathrm{ZnFe}_{2} \mathrm{O}_{4}$ (cubic, $a=0.8441 \mathrm{~nm}$, space group: $F d \overline{3} m, Z=8$; ICDD PDF \#22-1012) is a normal spinel at room temperature. Spinel structure is made up by a cubic close-packed array of oxygen atoms with tetrahedral (T) and octahedral (O) cavities. In the normal 2-3 spinels, one-eighth of the $\mathrm{T}$ sites and one-half of the $\mathrm{O}$ sites are filled by the divalent (A) cations $\left(\mathrm{Mg}^{2+}, \mathrm{Zn}^{2+}, \mathrm{Mn}^{2+}, \mathrm{Cd}^{2+}\right.$, etc. $)$ and the trivalent (B) cations $\left(\mathrm{Al}^{3+}, \mathrm{Fe}^{3+}, \mathrm{Cr}^{3+}\right.$ etc.), respectively, in the ratio $\mathrm{AB}_{2} \mathrm{O}_{4}$. The structural formula of zinc ferrite is usually written as $\left(\mathrm{Zn}_{1-} \delta^{2+} \mathrm{Fe} \delta^{3+}\right)\left[\mathrm{Zn}^{2+} \mathrm{Fe}_{2-} \delta^{3+}\right] \mathrm{O}_{4}{ }^{2-}$, where round ( ) and square [ ] brackets denote $\mathrm{T}$ and $\mathrm{O}$ sites of co-ordination, respectively, and $\delta$ represents the degree of inversion (defined by the fraction of the $\mathrm{T}$ sites occupied by

*e-mail: skp_bu@yahoo.com
B cations). There are two ordered configuration stable at low temperature, the one with $\delta=0$ (normal spinel) and the other with $\delta=1$ (inverse spinel). When the temperature increases, disorder takes place, since $\mathrm{A}$ and $\mathrm{B}$ cations undergo increasing intersite exchange over the three cation sites per formula unit (one $\mathrm{T}$ and two $\mathrm{O}$ sites). The completely random distribution of $\mathrm{A}$ and $\mathrm{B}$ cations over the three cation sites corresponds to $\delta=2 / 3$, which is asymptotically approached at very high temperatures. Same type of cation distribution is also observed in ball-milled samples ${ }^{6-7}$. The change in temperature or the change in milling parameter may result in change in the degree of inversion. It has been found that a metastable nanoscale structural state of mechanosynthesized $\mathrm{ZnFe}_{2} \mathrm{O}_{4}$ is characterized by a substantial displacement of $\mathrm{Fe}^{3+}$ cations to tetrahedral sites and of $\mathrm{Zn}^{2+}$ cations into octahedral sites. The inverse-normal transition in mechanosynthesized zinc ferrite proceeds rapidly in the temperature range $885-1073 \mathrm{~K}$ and the activation energy of the transition is $E \sim 72 \mathrm{~kJ}^{\mathrm{mol}}{ }^{-1[6]}$.

Formation of nanocrystalline $\mathrm{ZnFe}_{2} \mathrm{O}_{4}$ as normal and inverse spinel structures was noticed after ball-milling the stoichiometric mixture of $\mathrm{ZnO}$ and $\alpha-\mathrm{Fe}_{2} \mathrm{O}_{3}$ powders in open air for different lengths of time. Formation of nanocrystalline materials in the process of ball-milling leads to significant amount of structural and microstructural defects which can be characterized by X-ray diffraction and positron annihilation spectroscopy studies. 
The powder patterns of almost all the ball-milled materials, milled at different milling time are composed of a large number of overlapping reflections of $\alpha-\mathrm{Fe}_{2} \mathrm{O}_{3}$, $\mathrm{ZnO}$ and $\mathrm{ZnFe}_{2} \mathrm{O}_{4}$ (normal and inverse spinel) phases. The Rietveld analysis based on structure and microstructure refinement ${ }^{8-9}$ was adopted for precise determination of several microstructural parameters as well as relative phase abundance of such multiphase material.

The purpose of the present work is to characterize defect states of the zinc ferrite nanocomposites by positron annihilation lifetime spectroscopy (PALS) and establish their relationship with microstructure parameters obtained from X-ray analysis. PALS is a powerful technique to characterize defects in solid materials ${ }^{10}$. A nanostructured material contains unlimited grain boundaries and these boundaries are rich in lattice defects. Thus, PALS method can be effectively used to characterize nanostructures in terms of lattice imperfections. To the best of our knowledge, this type of analysis will help to understand the nature of deformation generated in the process of mechanical alloying in nanocrystalline ferrite powders.

\section{Experimental Method}

High-energy ball-milling of $\mathrm{ZnO}(\mathrm{M} / \mathrm{s}$ Merck, $99 \%$ purity) and $\alpha-\mathrm{Fe}_{2} \mathrm{O}_{3}(\mathrm{M} / \mathrm{s}$ Glaxo, $99 \%$ purity) mixture in 1:1 mol\% was conducted in a planetary ball mill (Model P5, M/S Fritsch, GmbH, Germany). The time of milling was varied from 30 minutes to 10 hours depending upon the rate of formation of zinc ferrite phase. The step-scan data (of step size $0.02^{\circ} 2 \theta$ and counting time 5 seconds) for the entire angular range $\left(15-80^{\circ} 2 \theta\right)$ of the unmilled mixture and all ball-milled samples were recorded using Ni-filtered $\mathrm{CuK} \alpha$ radiation from a highly stabilized and automated Philips X-ray generator (PW 1830) operated at $35 \mathrm{kV}$ and $25 \mathrm{~mA}$.
For PALS measurements, about $12 \mu \mathrm{Ci}{ }^{22} \mathrm{Na}$ activity was deposited and dried on a thin aluminium foil and was covered with an identical foil. This assembly was used as the positron source. The source correction was determined using a properly annealed defect- free aluminium sample. The PALS system used was a standard fast-fast coincidence set-up with two identical 1-inch tapered off $\mathrm{BaF}_{2}$ scintillator detectors fitted with XP 2020Q photomultiplier tubes. The time resolution obtained using ${ }^{60} \mathrm{Co}$ source with ${ }^{22} \mathrm{Na}$ gates was 285 ps. All lifetime spectra were analysed using PATFIT $88^{[11]}$ programme.

\section{Method of Analysis}

The Rietveld's powder structure refinement analysis ${ }^{12-15}$ of X-ray powder diffraction data using the Rietveld software MAUD 2.26 $6^{[9]}$ revealed the refined structural parameters, such as atomic coordinates, occupancies, lattice parameters, thermal parameters etc. and microstructural parameters, such as crystallite size and r.m.s. lattice strain etc. The experimental profiles were fitted with the most suitable pseudo-Voigt $(\mathrm{pV})$ analytical function ${ }^{15}$ because it takes individual care for both the crystallite size and strain broadening of the experimental profiles. Positron annihilation lifetime data were deconvoluted with three lifetime components using the PATFIT programme. A total source correction of $10 \%$ had been deducted while analysing the spectra.

\section{Results and Discussion}

\subsection{X-ray diffraction analysis}

Figure 1 shows the $\mathrm{X}$-ray powder diffraction patterns of unmilled and ball milled mixture of $\mathrm{ZnO}$ and $\alpha-\mathrm{Fe}_{2} \mathrm{O}_{3}$ powders milled for different durations. The powder pattern

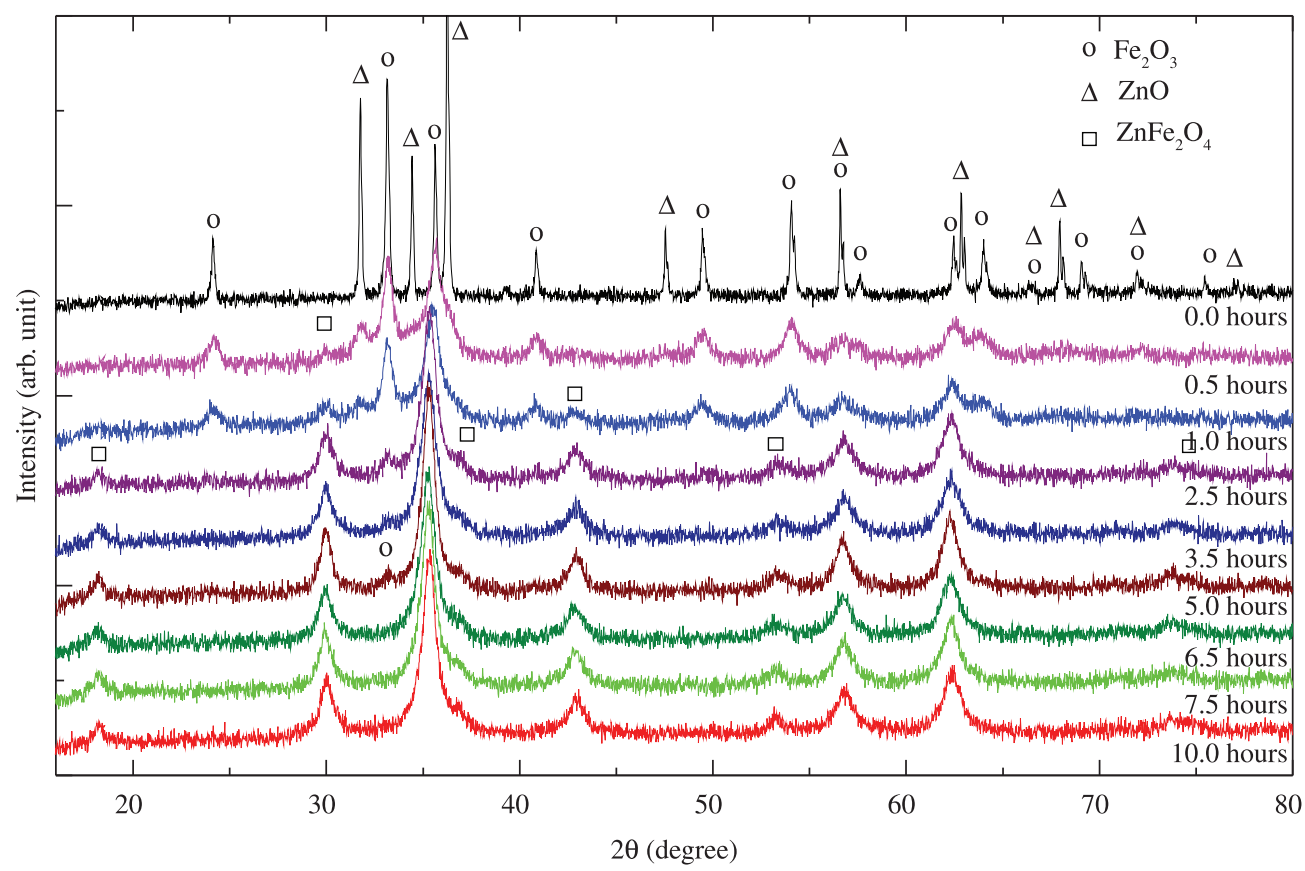

Figure 1. X-ray powder diffraction patterns of unmilled and ball milled $\mathrm{ZnO}-\alpha-\mathrm{Fe}_{2} \mathrm{O}_{3}$ mixture (1:1 mol\%) at BPMR 40:1. 
of unmilled mixture contained only the individual reflections of $\mathrm{ZnO}$ and $\alpha-\mathrm{Fe}_{2} \mathrm{O}_{3}$ phases and the precursors were free from impurities. It was noticed that in the course of ball milling the mixture, $\mathrm{ZnFe}_{2} \mathrm{O}_{4}$ phase was formed and its amount increased gradually with increasing milling time. After 30 minutes milling, the formation of $\mathrm{ZnFe}_{2} \mathrm{O}_{4}$ was noticed clearly with the appearance of $(220)\left(2 \theta=29.95^{\circ}\right)$ and strongest $(311)\left(2 \theta=35.3^{\circ}\right)$ reflections in the XRD pattern. It may also be noticed that the content of $\mathrm{ZnO}$ phase was reduced to a large extent in comparison to $\alpha-\mathrm{Fe}_{2} \mathrm{O}_{3}$ phase. It indicated that the $\mathrm{ZnO}$ phase was much prone to deformation fault as all the reflections were sufficiently broadened due to reduction in particle size and accumulation of lattice strain in the course of milling. As a result, solid-state diffusion between $\mathrm{ZnO}$ and $\alpha-\mathrm{Fe}_{2} \mathrm{O}_{3}$ nanoparticles enhanced extensively with increasing milling time. In the course of further milling, broadening as well as degree of overlapping of neighbouring reflections were increased with increasing milling time. After 2.5 hours of milling, except the strongest $(104)\left(2 \theta=33.18^{\circ}\right)$ reflection, all other reflections of $\alpha-\mathrm{Fe}_{2} \mathrm{O}_{3}$ were disappeared completely in the XRD pattern. It was the indication of either (i) significant reduction in content of the phase or (ii) significant increase in peak-broadening due to reduction in particle size and accumulation of lattice strain aroused from the high energy impact of milling or due to both these effects.
Concurrently, an incredible change in intensities of $\mathrm{ZnFe}_{2} \mathrm{O}_{4}$ reflections was observed in the XRD pattern. The rate of mechanosynthesis of $\mathrm{ZnFe}_{2} \mathrm{O}_{4}$ was then increased rapidly in course of milling. After 6.5 hours milling, all reflections of starting precursors were completely disappeared and it appeared that the $\mathrm{ZnFe}_{2} \mathrm{O}_{4}$ phase was completely grown up as the intensity distribution of the XRD pattern resembled perfectly in accordance with the ICDD PDF \# 22-1012. It was reported earlier that the present process of mechanosynthesis of zinc ferrite at room temperature by ball milling may also lead to the formation of a metastable inverse spinel structure. The inverse spinel zinc ferrite was derived by a substantial displacement of $\mathrm{Fe}^{3+}$ cations to tetrahedral $(\mathrm{T})$ sites and equal amount of $\mathrm{Zn}^{2+}$ cations into octahedral $(\mathrm{O})$ sites of the cubic close-packed anionic sublattice. After 2.5 hours milling, when the formation of $\mathrm{ZnFe}_{2} \mathrm{O}_{4}$ was almost completed, verification for formation of inverse spinel structure along with normal spinel was made because without considering the inverse spinel, fitting quality of XRD powder data was poor.

Figure 2 shows the comparison of the quality of profile fitting in the 2.5 hours and 10 hours-milled samples with and without consideration of inverse spinel structure of $\mathrm{ZnFe}_{2} \mathrm{O}_{4}$. It is evident from the figure that the inclusion of the inverse spinel with normal one improved the profile fitting quality significantly. It indicated towards the coexistence of both

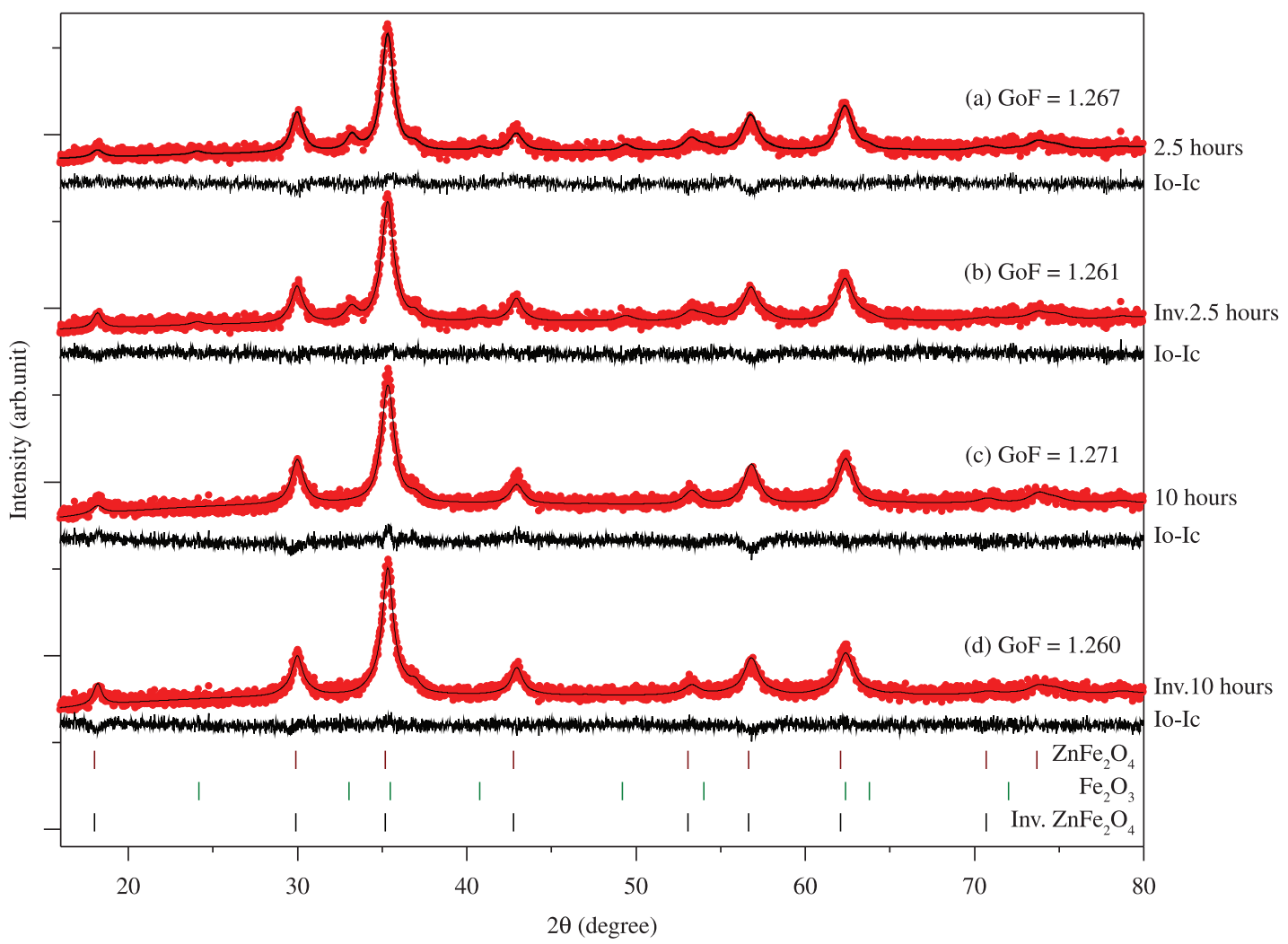

Figure 2. Calculated (-) and experimental ( ) X-ray powder diffraction patterns of ball milled $\mathrm{ZnO}-\alpha-\mathrm{Fe}_{2} \mathrm{O}_{3}$ (a) for 2.5 hours without inverse spinel (b) for 2.5 hours with inverse spinel (c) for 10 hours without inverse spinel (d) for 10 hours with inverse spinel revealed by Rietveld powder structure refinement analysis. 
the normal and inverse spinel structures of $\mathrm{ZnFe}_{2} \mathrm{O}_{4}$ in the samples prepared with higher milling time.

Figure 3 shows the dependence of relative phase abundances of different phases with increasing milling time. The content (wt. (\%)) of $\mathrm{ZnO}$ decreased rapidly but that of $\alpha-\mathrm{Fe}_{2} \mathrm{O}_{3}$ decreased slowly with increasing milling time. After 2.5 and 6.5 hours milling, $\mathrm{ZnO}$ and $\alpha-\mathrm{Fe}_{2} \mathrm{O}_{3}$ phases disappeared completely from the respective $\mathrm{XRD}$ patterns. The formation of normal spinel phase was noticed after 30 minutes of milling and its content increased continuously (9.4-41.3 wt. (\%)) up to 2.5 hours milling. Simultaneously, almost equal amount (40.1 wt. (\%)) of inverse spinel phase was noticed to form. Content of normal phase remained almost unchanged up to 10 hours milling but that of inverse phase increased to a large extent after 6.5 hours milling when $\alpha-\mathrm{Fe}_{2} \mathrm{O}_{3}$ was completely utilized for making exact stoichiometric (1:1 mol\%) Zn-ferrite phase. This sudden increase in inverse phase content was essentially due to occupancy of octahedral vacancies by $\mathrm{Fe}^{3+}$ cations of inverse spinel structures ${ }^{16}$.

The nature of variation of crystallite sizes (D) of $\mathrm{ZnO}, \alpha-\mathrm{Fe}_{2} \mathrm{O}_{3}$ and ferrite phases are shown in Figure 4a. Crystallite sizes of all the phases were considered to be

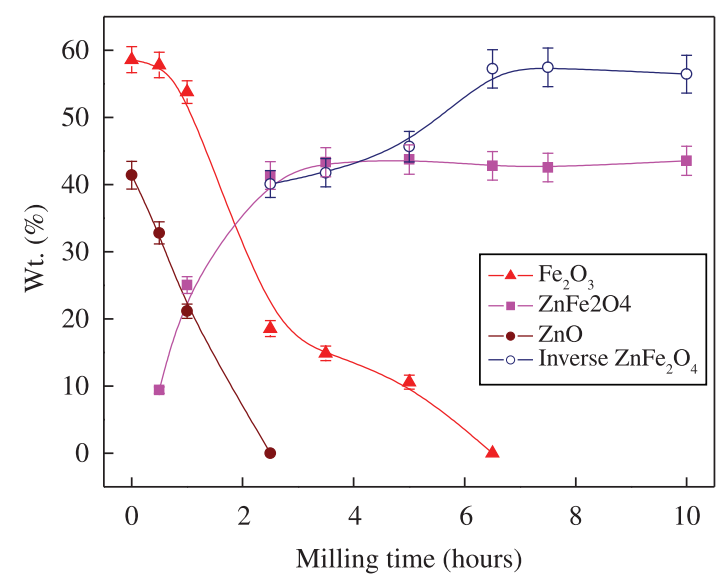

Figure 3. Variation of phase content (wt. (\%)) of different phase with increasing milling time.

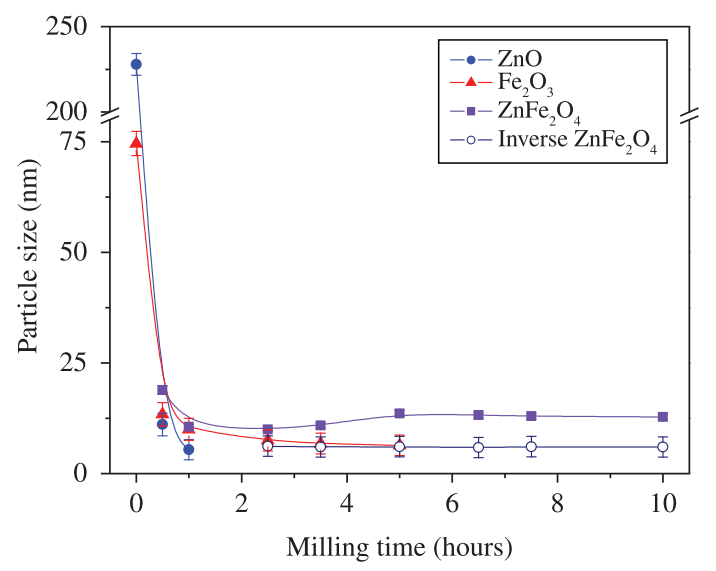

(a) isotropic. The crystallite size of $\mathrm{ZnO}$ decreased rapidly to $\sim 11 \mathrm{~nm}$ within 30 minutes milling and then decreased slowly with increasing milling time. Crystallite size $\alpha-\mathrm{Fe}_{2} \mathrm{O}_{3}$ phase was reduced from $\sim 75 \mathrm{~nm}$ to $\sim 13 \mathrm{~nm}$ within 30 minutes ball milling and then decreased slowly to a saturation value $\sim 7 \mathrm{~nm}$. Normal $\mathrm{ZnFe}_{2} \mathrm{O}_{4}$ phase was formed after 30 minutes of milling with $\sim 19 \mathrm{~nm}$ crystallite size and then reduced to $\sim 10 \mathrm{~nm}$ after 2.5 hours of milling. This decrease in normal spinel crystallite size was manifested in the growth of very small crystallite size of $\sim 6 \mathrm{~nm}$ of inverse spinel phase after 2.5 hours of milling. After complete formation of both spinel phases, heat energy produced by high energy impacts was utilised to release the accumulated strain inside the nanoparticles and as a result, the crystallite size increased to a small extent. This effect may also be explained as the agglomeration of nanometric particles by re-welding mechanism.

The nature of variation of r.m.s lattice strain with increasing milling time is shown in Figure 4b. It is obvious that the strain value of normal spinel lattice increased very rapidly within 30 minutes and then increased very slowly with increasing milling time, but after 2.5 hours milling, lattice strain suddenly started to release and after 5 hours milling it reached a saturation value and remained almost unchanged with increasing milling time. This nature of variation corroborates the variation of particle size with increasing milling time.

\subsection{Positron annihilation spectroscopy}

Positron annihilation lifetime spectra (PALS) of all the ball-milled samples were deconvoluted using three lifetimecomponents $\tau_{1}, \tau_{2}$ and $\tau 3$ with corresponding intensities $I_{1}$, $\mathrm{I}_{2}$ and $\mathrm{I}_{3}$ respectively. In general, for bulk polycrystalline samples, the shortest positron lifetime $\left(\tau_{1}\right)$ is assigned to the free annihilation of positrons at defect-free sites, the intermediate lifetime $\left(\tau_{2}\right)$ is assigned to the lifetime of positrons trapped at the defect sites (mono or di-vacancies) and the longest one $(\tau 3)$ to the pick-off annihilation of o-Ps atoms formed inside large voids. But, in the case of polycrystalline samples with crystallite size of the order

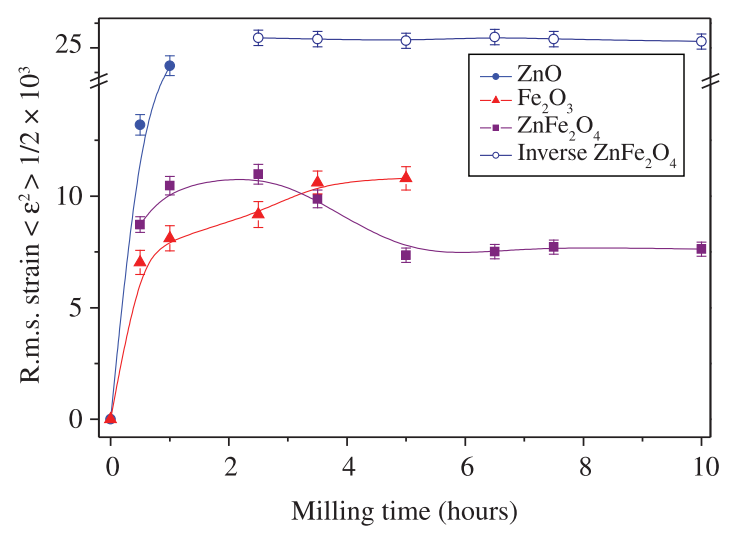

(b)

Figure 4. a) Variation of crystallite size of $\mathrm{ZnO}, \mathrm{Fe}_{2} \mathrm{O}_{3}, \mathrm{ZnFe}_{2} \mathrm{O}_{4}$ and inverse $\mathrm{ZnFe}_{2} \mathrm{O}_{4}$ with increasing milling time. b) Variation of r.m.s strain of $\mathrm{ZnO}, \mathrm{Fe}_{2} \mathrm{O}_{3}, \mathrm{ZnFe}_{2} \mathrm{O}_{4}$ and inverse $\mathrm{ZnFe}_{2} \mathrm{O}_{4}$ with increasing milling time. 
of a few tens of nanometers, the assignments of lifetime parameters are different. When crystallite sizes become smaller compared to the mean positron diffusion length $(\sim 100 \mathrm{~nm})$, positrons pass through the grains and annihilate mainly in the grain boundary regions. In this case, the shortest lifetime $\left(\tau_{1}\right)$ represents the weighted average of positron lifetimes at the grain boundary defects (mono or di-vacancies) and the lifetime corresponding to annihilation with free electrons residing at the grain boundaries. The intermediate lifetime $\tau_{2}$ corresponds to annihilations at the triple junctions. Triple junctions are open volumes present at the intersection of three or more grain boundaries and their size is of the order of 8-10 missing atoms. The fraction of positrons that gets annihilated inside a grain depends on the positron 'trapping capability' of the defects present at the grain boundaries. The more is the positron trapping at grain boundary defects, the less is the probability of annihilation with free electrons inside a grain.

Figure 5 shows the variation of mean positron lifetime $\left(\tau_{\mathrm{m}}\right)$ for $\mathrm{ZnO}+\alpha-\mathrm{Fe}_{2} \mathrm{O}_{3}$ nanocomposites as a function of ball-milling duration. $\tau_{\mathrm{m}}$ is related to average defect density and is defined as

$$
\tau_{m}=\frac{I_{1} \tau_{1}+I_{2} \tau_{2}+I_{3} \tau_{3}}{I_{1}+I_{2}+I_{3}}
$$

For a given type (size) of defect, higher the defect density larger will be the value of $\tau_{\mathrm{m}}$. It is clear that $\tau_{\mathrm{m}}$ remains more or less constant throughout the ball-milling process. This implies that the overall defect density, as seen by the positrons remains more or less constant although ball-milling is expected to introduce several changes in structure and phase content of the nanocomposite. To obtain an insight into the positron capture mechanism at various trapping centers, the variation of the individual lifetime parameters with ball-milling duration is to be seen.

Figure 6 shows the variation of positron lifetimes $\tau_{1}, \tau_{2}$ and intensity $\mathrm{I}_{2}$ with milling duration. Before milling, i.e. at milling duration $\mathrm{t}=0$ hours, lifetime $\tau_{1}$ may be ascribed to free annihilation of positrons in the bulk $\alpha-\mathrm{Fe}_{2} \mathrm{O}_{3}$ and $\mathrm{ZnO}$ crystals. Positron trapping can be also expected in the grain boundary defects of $\alpha-\mathrm{Fe}_{2} \mathrm{O}_{3}$ as its average crystallite

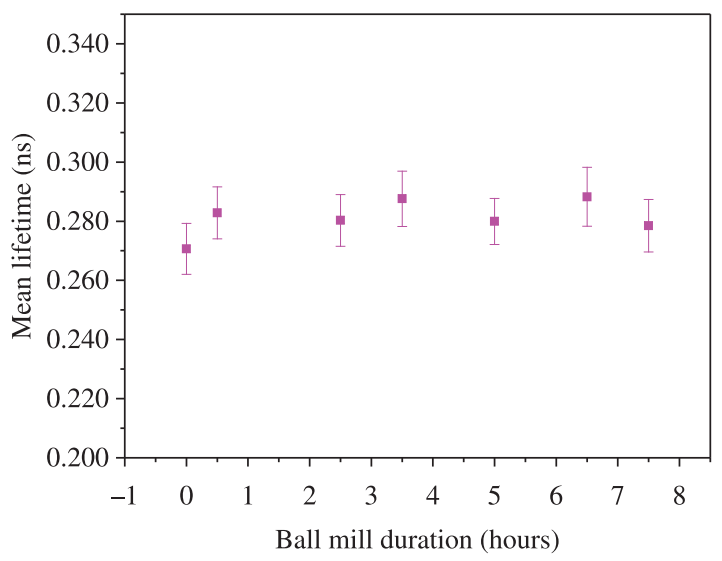

Figure 5. Variation of mean-lifetime $\left(\tau_{\mathrm{m}}\right)$ for $\mathrm{ZnO}+\alpha-\mathrm{Fe}_{2} \mathrm{O}_{3}$ nanocomposites as a function of ball-mill duration. size is $\sim 75 \mathrm{~nm}$ (Figure 4a), which is less than positron diffusion length in solids. $\tau 2$ may be ascribed to the lifetime of positrons trapped at the defect sites viz., grain boundary defects in $\mathrm{ZnO}$ and triple-junctions of $\alpha-\mathrm{Fe}_{2} \mathrm{O}_{3}$ nanocrystals.

After 30 minutes of milling, the XRD analysis shows that the sample contains nanocrystals of $\mathrm{ZnO}, \alpha-\mathrm{Fe}_{2} \mathrm{O}_{3}$ and $\mathrm{ZnFe}_{2} \mathrm{O}_{4}$ (Figures 1 and 3 ). Hence the shortest lifetime $\left(\tau_{1}\right)$ after milling the mixture for 30 minutes, may be assigned to the mixed lifetime of positrons trapped at defects (mono or di-vacancies) present at the grain boundaries of all the nanocrystals $(\mathrm{ZnO}$, $\alpha-\mathrm{Fe}_{2} \mathrm{O}_{3}$ and $\mathrm{ZnFe}_{2} \mathrm{O}_{4}$ ) present in the sample and also to the free annihilation inside these nanocrystalline grains. The intermediate lifetime $\left(\tau_{2}\right)$ has been assigned to the lifetime of positrons trapped at the triple junction formed at the intersection of three or more nanocrystalline grains. Similar assignment of lifetimes was seen to successfully explain the results obtained in case of $\mathrm{ZnO}$ nanocrystals ${ }^{17} . \tau_{1}$ and $\tau_{2}$ in this case can be expressed as follows

$\tau_{1}=\sum_{i}\left(\left.n_{i} \tau_{i}\right|_{G B}+\left.n_{i} \tau_{i}\right|_{B}\right)$

and,

$\tau_{2}=\sum_{i}\left(\left.n_{i} \tau_{i}\right|_{T P}\right)$

where $i$ stands for species of nanocrystalline grains viz., $\mathrm{ZnO}$, $\alpha-\mathrm{Fe}_{2} \mathrm{O}_{3}$ or $\mathrm{ZnFe}_{2} \mathrm{O}_{4}, G B$ stands for grain-boundary, $B$ stands for bulk i.e. the defect free sites inside a grain, $n$ stands for the fraction of positrons annihilating in a particular site (GB or B) of a particular type of grain $i$, and $T P$ stands for triple junction.

Upto a milling duration of 3.5 hours, $\tau_{1}$ shows a slight increasing trend. This is because of the fact that the crystallite sizes become smaller as the ball-milling duration is increased which in turn increases the surface area to volume ratio. As a result of this, the contribution from the annihilation at grain boundary increases resulting in the increase in the value of $\tau_{1}$. However $\tau_{2}$ shows a decreasing trend as milling hour changes from 30 minutes to 2.5 hours and remains more or less same up to milling time 3 hours. The fall in $\tau_{2}$ may be ascribed to the decrease in weight percentage of $\alpha-\mathrm{Fe}_{2} \mathrm{O}_{3}$ (from 58.6 to $14.9 \%$ ) with increase in milling time. Disappearance of $\alpha-\mathrm{Fe}_{2} \mathrm{O}_{3}$ from the sample in the course of milling indicates decrease in the contribution of triple junctions to $\tau_{2}$. It can also be seen that the corresponding intensity $\mathrm{I}_{2}$, which gives an idea of the defect concentration related to $\tau_{2}$, maintains a steady value up to 3.5 hours of milling. Another point to be noted is that though the wt. ( $\%)$ of $\alpha-\mathrm{Fe}_{2} \mathrm{O}_{3}$ phase changes, $\tau_{1}$ still remains more or less constant in the region of 2.5 to 3.5 hours of milling. A decrease in wt. $(\%)$ could have decreased the contribution of annihilation at triple junction of $\alpha-\mathrm{Fe}_{2} \mathrm{O}_{3}$ nanocrystals. This may be explained as following manner. Since the crystallite size of $\alpha-\mathrm{Fe}_{2} \mathrm{O}_{3}$ were also seen to decrease in this region, the fraction of positrons annihilating at the grain boundaries becomes more, thereby compensating the decrease in the value of $\tau_{1}$. However $\tau_{1}$ was seen to decrease after milling the sample for 5 hours. The phase content of the sample at this stage includes $\alpha-\mathrm{Fe}_{2} \mathrm{O}_{3}$, normal spinel $\mathrm{ZnFe}_{2} \mathrm{O}_{4}$ and inverse spinel $\mathrm{ZnFe}_{2} \mathrm{O}_{4}$ phases. Their content and grain sizes do not change much in this milling stage compared to the previous milling stage ( 3.5 hours). The only change is a 
substantial decrease in r.m.s. strain value of the normal spinel $\mathrm{ZnFe}_{2} \mathrm{O}_{4}$ structure $^{18}$. Lattice strain depends on the lattice imperfection and lattice imperfections may arise from the non-stoichiometric composition of the crystal structure. In this case, decrease in r.m.s. strain value of the normal spinel ferrite structure strongly indicates the removal of vacancy type defects, which arises out of non-stoichiometric composition in the ferrite structure. The removal of defects, from the normal
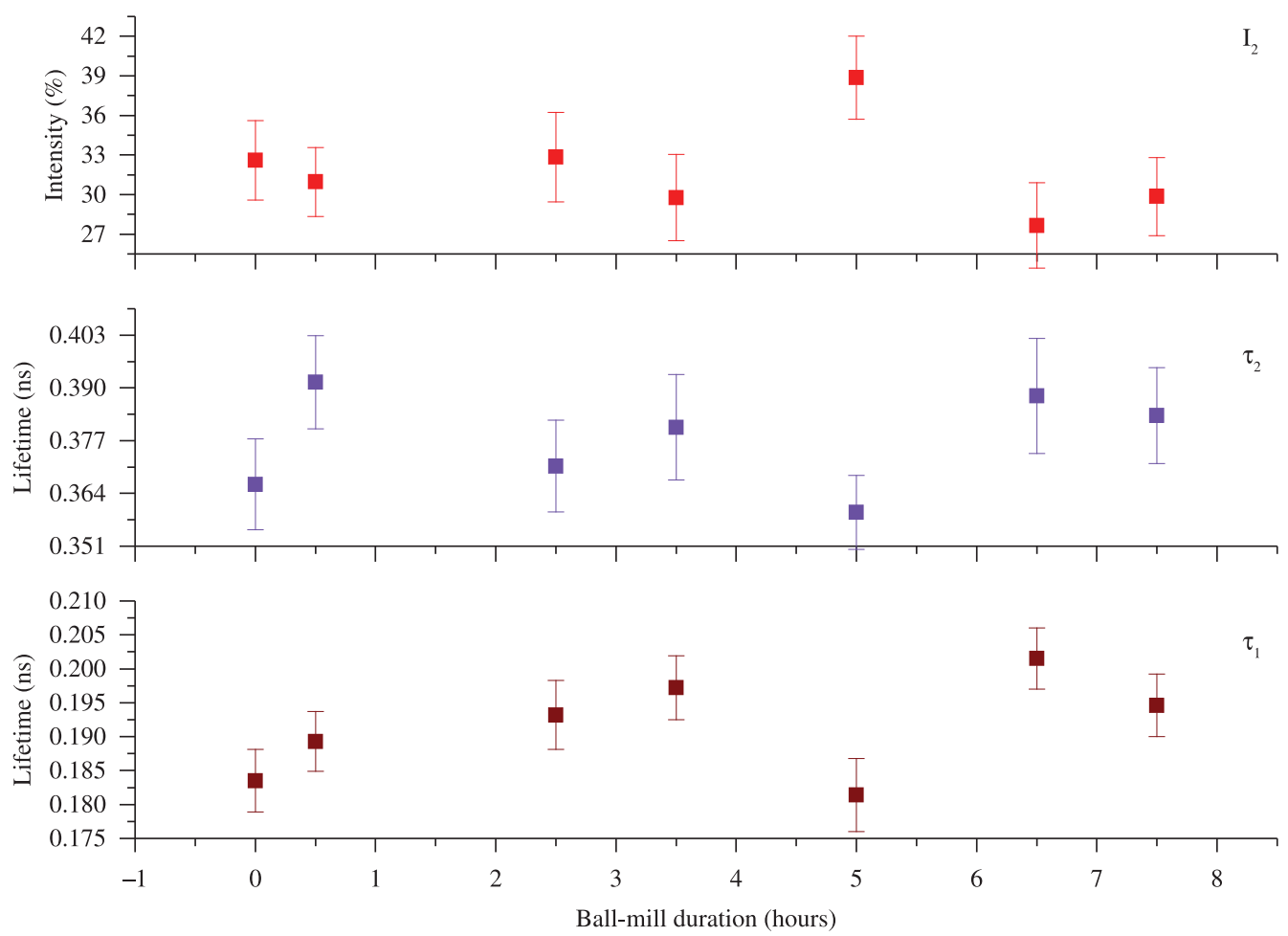

Figure 6. Variation of $\tau_{1}, \tau_{2}$ and $\mathrm{I}_{2}$ for $\mathrm{ZnO}+\alpha-\mathrm{Fe}_{2} \mathrm{O}_{3}$ nanocomposites as a function of ball-mill duration.
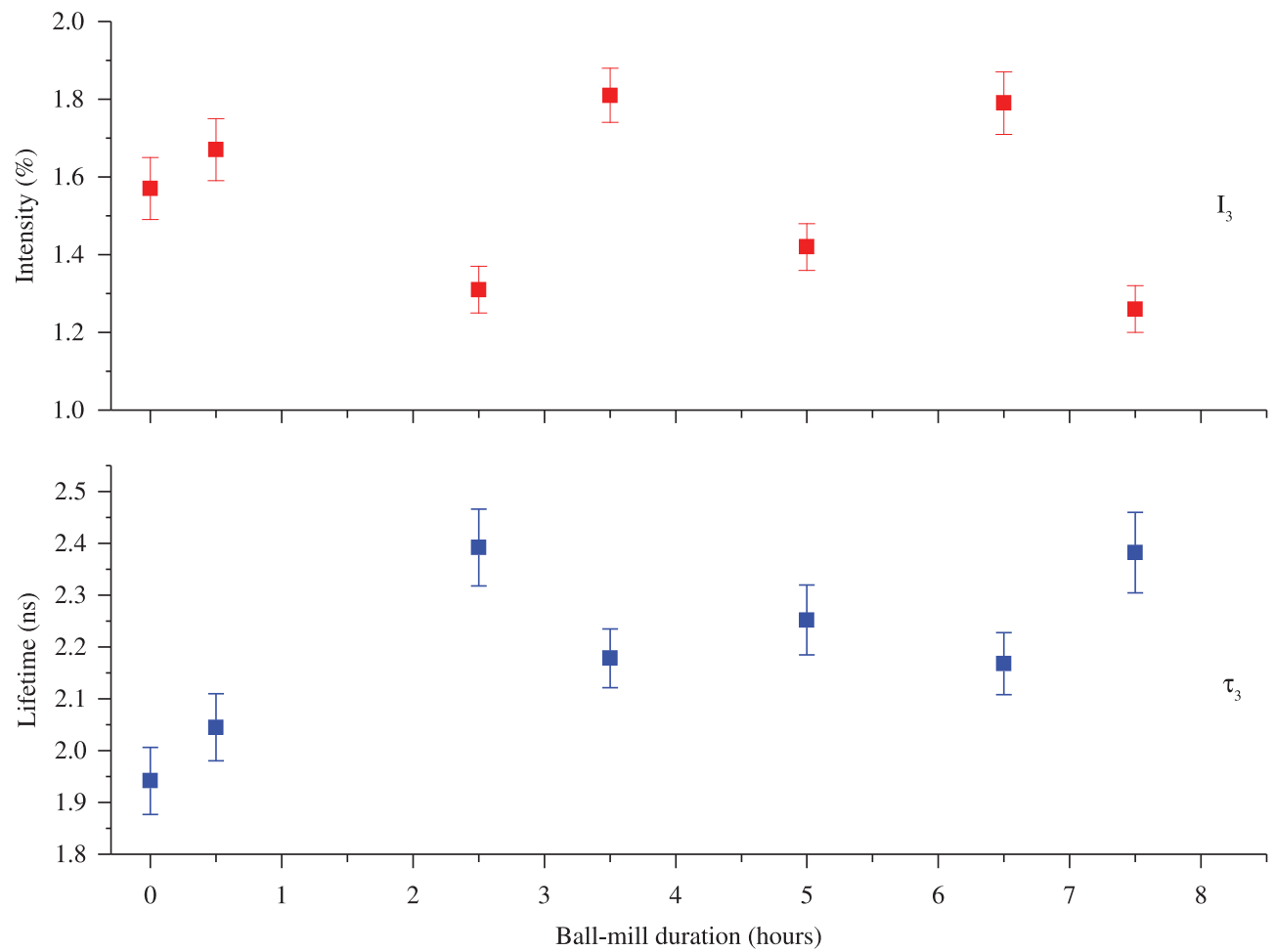

Figure 7. Variation of $\tau_{3}$ and $\mathrm{I}_{3}$ for $\mathrm{ZnO}+\alpha-\mathrm{Fe}_{2} \mathrm{O}_{3}$ nanocomposites as a function of ball-mill duration. 
spinel structure, leads to a decrease in contribution of defect related lifetime to the lifetime component $\tau_{1}$, leading to a reduction in its value. After 6.5 hours of milling, $\tau_{1}$ again increases. At this milling stage, it was seen that the $\alpha-\mathrm{Fe}_{2} \mathrm{O}_{3}$ phase completely vanishes from the composite sample. Simultaneously, the wt. (\%) of inverse spinel component also increases after milling the sample for 6.5 hours. This indicates a reduction in the contribution of the free annihilation of positrons in the $\alpha-\mathrm{Fe}_{2} \mathrm{O}_{3}$ crystals as well as of the annihilation at the grain boundary defect sites in the inverse spinel structure resulting in an overall increase in $\tau_{1}$ value. However, as the complete solid solution of $\alpha-\mathrm{Fe}_{2} \mathrm{O}_{3}$ results in increase the wt. (\%) of inverse spinel $\mathrm{ZnFe}_{2} \mathrm{O}_{4}$, the value of $\tau_{2}$ did not change at this stage.

Figure 7 shows the variation of $\tau_{3}$ and $\mathrm{I}_{3}$ as a function of ball-mill duration. Except an initial increase, value of $\tau_{3}$ remains more or less steady. However, $\mathrm{I}_{3}$ shows some fluctuations in its behavior. These fluctuations do not correlate themselves anyhow to the structural changes and hence are not discussed in this article.

\section{Conclusion}

The quantitative analysis of the XRD data evaluated on the basis of Rietveld's powder structure refinement method yielded detailed information about the structure and

\section{References}

1. Goldman A. Modern Ferrite Technology. Van Nostrand Reinhold: New York; 1990.

2. Berskovsky BM, McDvedev VF and Krakov MS. Magnetic Fluids: Engineering Applications. Oxford: Oxford University Press; 1993.

3. AyalaREand MarshDW. Characterization and long range reactivity of zinc ferrite in high temperature desulfurization processes. Industrial \& Engineering Chemistry Research. 1991; 30:55-60. http://dx.doi.org/10.1021/ie00049a009

4. Bissett LA and Strickland LD. Analysis of a fixed-bed gasifier IGCC configuration. Industrial \& Engineering Chemistry Research. 1991; 30:170-176. http://dx.doi.org/10.1021/ ie00049a025

5. Sack RO and Ghiorso MS. An internally consistent model for the thermodynamic properties of $\mathrm{Fe} \_\mathrm{Mg}$ titanomagnetite aluminate spinels. Contributions to Mineralogy and Petrology. 1991; 106:474-505. http://dx.doi.org/10.1007/ BF00321989

6. Druska P, Steinike U and Sepelak V. Surface structure of mechanically activated and of mechanosynthesized zinc ferrite. Journal of Solid State Chemistry. 1999; 146:13-21. http:// dx.doi.org/10.1006/jssc.1998.8284

7. Chinnasamy $\mathrm{CN}$, Narayanasamy A, Ponpandian N, Chattopadhyay K, Guerault H, and Greneche J-M. Magnetic properties of nanostructured ferrimagnetic zinc ferrite. Journal of Physics Condensed Matter. 2000; 12:7795-7805. http:// dx.doi.org/10.1088/0953-8984/12/35/314

8. Lutterotti L, Scardi P and Maistrelli P.LSI- a computer program for simultaneous refinement of material structure and microstructure. Journal of Applied Crystallography. 1992; 25:459-462. http:// dx.doi.org/10.1107/S0021889892001122

9. Lutterotti L. MAUD. version 2.26. 2011. Available from: $<$ http://www.ing.unitn.it/ maud $>$. microstructure of mechanosysthesized nanoscale zinc ferrite as well as the distribution of cations in the spinel ferrite. The main feature of the structural disorder of mechanosynthesized zinc ferrite was the defect induced inverse spinel phase transition. The degree of inversion increased rapidly with increasing milling time and then wt. (\%) of inverse phase approached towards a saturation value. Positron annihilation lifetime data shows that the mean lifetime $\tau_{\mathrm{m}}$ does not change much with ball milling durations. This implies that the overall defect density, as seen by the positrons remains more or less constant during milling. The variation of individual lifetimes $\tau_{1}$ and $\tau_{2}$ and corresponding intensities $I_{1}$ and $I_{2}$ shows evaluation of different phases with milling duration and confirms the formation of inverse spinel ferrite structure.

\section{Acknowledgement}

One of the authors, SKP, wishes to thank the University Grant Commission (UGC) India, for granting CAS-I programme under the thrust area "Condensed Matter Physics including Laser applications" to the Department of Physics, The University of Burdwan under the financial assistance of which the work has been carried out. We are also grateful to UGC-DAE-CSR, Kolkata centre for providing Positron annihilation spectroscopy facility.

10. Krause-Rehberg R and Leipner HS. Positron Annihilation in Semiconductors: Solid-State Sciences. Berlin: Springer; 1999. p. 127.

11. Kirkegaard P and Eldrup M. POSITRONFIT: a versatile program for analysing positron lifetime spectra. Computer Physics Communications. 1972; 3:240-255. http://dx.doi. org/10.1016/0010-4655(72)90070-7

12. Rietveld HM. Line profiles of neutron powder-diffraction peaks for structure refinement. Acta Crystallographica. 1967; 22:151-152. http://dx.doi.org/10.1107/S0365110X67000234

13. Rietveld HM. A profile refinement method for nuclear and magnetic structures. Journal of Applied Crystallography. 1969; 2:65-71. http://dx.doi.org/10.1107/ S0021889869006558

14. Sain S, Patra S and Pradhan SK. Microstructure and optical band-gap of mechano-synthesized $\mathrm{Cd}_{x} \mathrm{Zn}_{1-x} \mathrm{~S}$ quantum dots. Journal of Physics D. 2011; 44: Article ID 075101.

15. Young RA and Willes DB. Profile shape functions in Rietveld refinements. Journal of Applied Crystallography. 1982; 15:430-438. http://dx.doi.org/10.1107/S002188988201231X

16. Wei Q-M, Li J-B and Chen Y-J. Cation distribution and infrared properties of $\mathrm{Ni}_{x} \mathrm{Mn}_{1-x} \mathrm{Fe}_{2} \mathrm{O}_{4}$ ferrites. Journal of Materials Science. 2001; 36:5115-5118. http://dx.doi. org/10.1023/A:1012473207424

17. Mishra AK, Chaudhuri SK, Mukherjee S, Priyam A, Saha A and Das D. Characterization of defects in $\mathrm{ZnO}$ nanocrystals: Photoluminescence and positron annihilation spectroscopic studies. Journal of Applied Physics. 2007; 102:103514-103514-6. http://dx.doi.org/10.1063/1.2817598

18. Bid S and Pradhan SK. Preparation of zinc ferrite by highenergy ball-milling and microstructure characterization by Rietveld's analysis. Materials Chemistry and Physics. 2003; 82:27-37. http://dx.doi.org/10.1016/S02540584(03)00169-X 